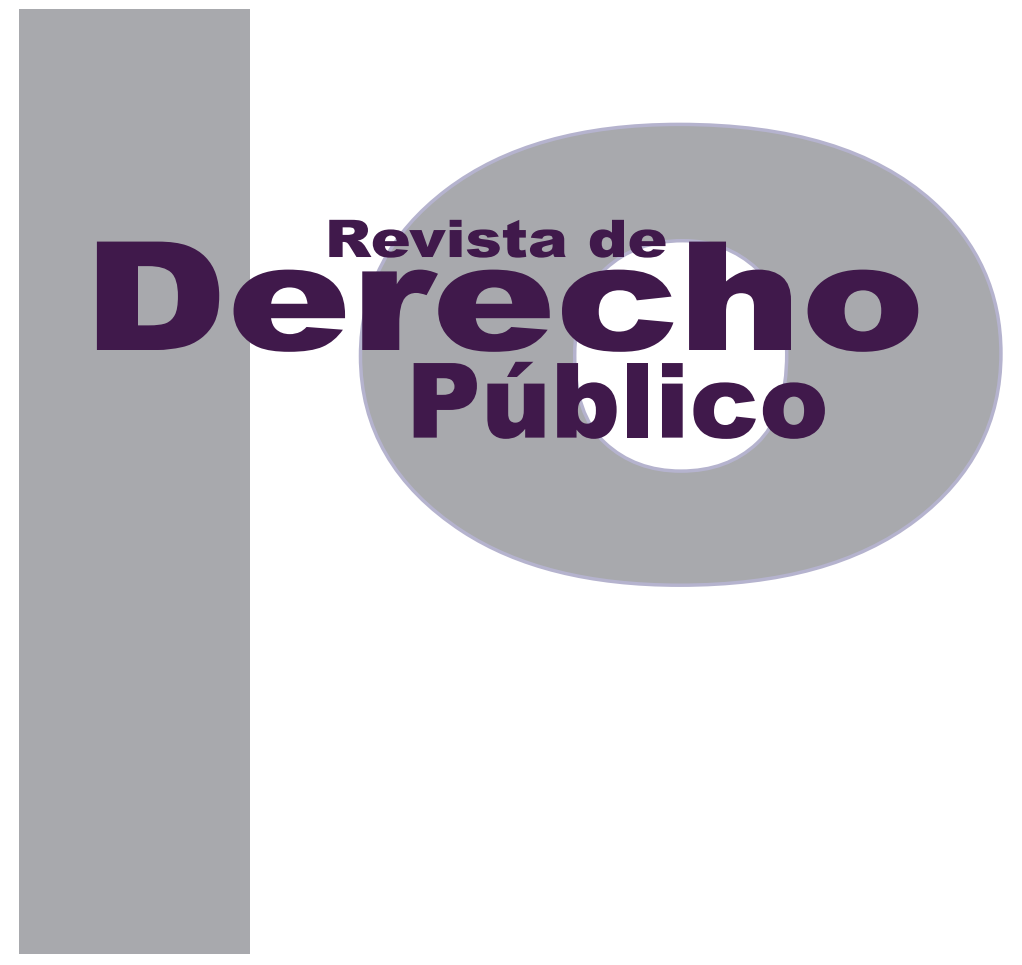

\title{
MUJER VS. ABOGADA: SOBRE LA CUESTIÓN DE GÉNERO EN LA PROFESIÓN LEGAL
}

\author{
María del Pilar CARMONA SUÁREz
}

Artículo de investigación científica y tecnológica

DOI: http://dx.doi.org/10.15425/redepub.35.2015.15

Universidad de los Andes

Facultad de Derecho

Rev. derecho publico No.35

julio - diciembre de 2015. ISSN 1909-7778 


\section{Mujer vs. Abogada: sobre la cuestión de género en la profesión legal}

\section{Resumen}

Esta investigación pretende explorar si las abogadas identificamos, o no, como discriminatorias, prácticas de distinción, exclusión o restricción por género en el ámbito profesional. Así mismo, pregunta por las formas en que asumimos dichas situaciones y las estrategias que usamos para hacerles frente. La finalidad es indagar acerca de la posibilidad de generar agencia en torno a situaciones que pueden considerarse discriminatorias en la práctica profesional

Palabras clave: mujeres, profesión legal, derecho, discriminación, género.

\section{Woman vs. Lawyer: on the question of gender in the legal profession}

\section{Abstract}

This research aims to explore whether or not we as female lawyers have identified discriminatory practices of gender distinction, exclusion or restriction in the professional field. This piece also asks about the ways in which we handle those situations and the strategies used to address them. The purpose is to inquire about the possibility of generating awareness about situations that may be considered discriminatory in the practice of this profession.

Keywords: women, legal profession, law, discrimination, gender.

\section{Mulher vs. Advogada: sobre a questão de gênero na profissão legal Resumo}

Esta investigação pretende explorar se as advogadas identificam, ou não, como discriminatórias, práticas de distinção, exclusão ou restrição por gênero no âmbito profissional. Assim mesmo, pergunta pelas formas em que assumimos ditas situações e as estratégias que usamos para enfrentá-las. A finalidade é indagar acerca da possibilidade de gerar agência em torno de situações que podem considerar-se discriminatórias na prática profissional.

Palavras-chave: mulheres, profissão legal, direito, discriminação, gênero. 


\title{
Mujer vs. Abogada: sobre la cuestión de género en la profesión legal*
}

\author{
María del Pilar Carmona Suárez ${ }^{* *}$
}

\section{SUMARIO}

Introducción - A. Consideraciones preliminares - B. La pregunta por la discriminación - I. MARCO TEÓRICO - A. La entrada de las mujeres a la profesión - B. Avance, situación y permanencia de las mujeres en la profesión - 1. Mecanismos de exclusión relacionados con la ausencia de las mujeres en los escalones más altos de la profesión - 2. Movilidad profesional - 3. Polarización y segregación - C. Los cambios en la profesión por el ingreso de las mujeres - 1. Los cambios en estatus, prestigio e ingresos - 2. Los cambios cualitativos en la profesión - 3. Los dilemas del impacto cualitativo de las mujeres en la profesión - II. MARCO METODOLÓGICO - A. Delimitación del campo de investigación - B. La entrevista - C. La muestra - D. Análisis de resultados - 1. Percepción sobre la discriminación en la profesión - 2. Respuesta a circunstancias de discriminación, exclusión o restricción - 3. Percepciones sobre la existencia de una cultura masculina del derecho - 4. Sensibilidad al género como variable social relevante - III. CONCLUSIONES - Referencias.

* Cómo citar este artículo: Carmona Suárez, M. del P. (Diciembre, 2015). Mujer vs. abogada: sobre la cuestión de género en la profesión legal. Revista de Derecho Público, 35. Universidad de los Andes (Colombia).

Este artículo es producto del trabajo de investigación realizado en la Maestría en Derecho de la Universidad de los Andes entre 2010-2012. Un agradecimiento especial a Isabel Cristina Jaramillo Sierra quien dirigió la investigación, sin su apoyo este trabajo no habría sido posible.

** Abogada y magíster en Derecho de la Universidad de los Andes. Investigadora adscrita y gestora de proyectos de investigación del Centro de Investigaciones Sociojurídicas de la Universidad de los Andes. Correo: m-carmon@uniandes.edu.co 
Introducción

Este artículo habla sobre el ejercicio profesional de las mujeres en el derecho. Se pregunta por la discriminación en una profesión en la que la tendencia al mejoramiento cuantitativo coexiste con formas de segregación por sexo (Bergallo, 2006). Las mujeres, a pesar de contar con los mismos activos de capital humano que los hombres en cuanto a educación y experiencia profesional, siguen siendo dejadas en los márgenes del poder y el privilegio, y nos vemos muchas veces obligadas a abandonar carreras profesionales en ascenso debido a permanencias culturales que asignan las tareas domésticas y de cuidado preponderantemente en cabeza de las mujeres.

Aunque en el mundo profesional las barreras de ingreso e inclusión para las mujeres se han visto disminuidas, las diferencias entre hombres y mujeres en materia de posición, ingresos y estatus persisten. Estas diferencias continúan siendo explicadas en la cotidianidad en función de la idea de elección individual, imágenes de oportunidad y teorías del capital humano, restándole importancia a barreras estructurales e institucionales, factores intangibles de capital social y cultural, así como sesgos y restricciones culturales que limitan las posibilidades de ascenso y permanencia de las mujeres en el ámbito profesional.

Las dinámicas de distinción, exclusión o restricción asociadas a factores estructurales, esquemas culturales y sesgos, continúan operando de manera soterrada o racionalmente justificada.
Esta investigación pretende explorar si las abogadas identifican, o no, como discriminatorias, prácticas consideradas como tales en la literatura especializada. Así mismo, se pregunta por las formas en que asumen dichas situaciones $y$ las estrategias que usamos para hacerles frente. El propósito es indagar acerca de la posibilidad de generar agencia en torno a situaciones de discriminación y desventaja en la profesión.

Para abordar las inquietudes planteadas este estudio se propuso aproximarse a la experiencia de las mujeres abogadas en el ejercicio de la profesión. Partió de una revisión de literatura especializada para comprender cómo ocurre la discriminación hacia las abogadas en la profesión legal, así como para identificar conceptos y variables relevantes que dieran sentido a la experiencia de las mujeres en la labor profesional. El estudio continuó con una investigación cualitativa en la que participaron 17 mujeres que ejercían o habían ejercido como abogadas en el sector público, en Bogotá.

El trabajo de campo se propuso examinar las percepciones de estas abogadas sobre su experiencia en el derecho, partiendo de la hipótesis de que las mujeres abogadas no identificaban la discriminación ni el impacto de género en el ejercicio profesional, porque al hacerlo corrían el riesgo de perder relevancia y legitimidad en una profesión con una cultura eminentemente masculina, en la que sus reivindicaciones son descalificadas como comportamientos débiles, sin autoridad y poco asertivos, que no son compatibles con la figura del abogado exitoso. 
Lo que muestran los hallazgos del trabajo de campo es que las abogadas que participaron, identifican dinámicas de discriminación. No obstante, responden a estas situaciones desde el ámbito individual, invirtiendo en recursos tradicionales de capital humano. La posibilidad de pensar la discriminación en la profesión como un asunto de grupo, alrededor del cual construir un proyecto común o pensar en la reforma de la profesión, es una posibilidad aún por explorar.

\section{A. Consideraciones preliminares}

En Colombia existe la intención constitucional de hacer de este un país igualitario. El artículo 13 de la Carta política establece:

Todas las personas nacen libres e iguales ante la ley, recibirán la misma protección y trato de las autoridades y gozarán de los mismos derechos, libertades y oportunidades sin ninguna discriminación por razones de sexo, raza, origen nacional o familiar, lengua, religión, opinión política o filosófica.

En materia legal existe un cúmulo de normas que propenden por la igualdad de género. El artículo 2 de la Ley 823 de 2003, por la cual se dictan normas sobre igualdad de oportunidades para las mujeres, dispone:

La presente ley se fundamenta en el reconocimiento constitucional de la igualdad jurídica, real y efectiva de derechos y oportunidades de mujeres y hombres, en el respeto de la dignidad humana y en los principios consagrados en los acuerdos internacionales sobre esta materia.
La igualdad de oportunidades para las mujeres, y especialmente para las niñas, es parte inalienable, imprescriptible e indivisible de los derechos humanos y libertades fundamentales. [Cursivas fuera del texto].

En el tema que nos ocupa, existen diversas disposiciones normativas encaminadas a garantizar la igualdad de mujeres y hombres en el ámbito laboral (Ley 1413 de 2010, Ley 1496 de 2011, Ley 1468 de 2011, Decreto 4463 de 2011).

Aunque no existen barreras normativas y la participación laboral de las mujeres aumentó de un $30 \%$ a un 60\% entre 1976-2006, después de haber mejorado sus recursos de capital humano y haber sobrepasado a los hombres en la obtención de títulos universitarios, resultados diferenciables para hombres y mujeres en el campo profesional sugieren que en la práctica no se ha logrado la igualdad establecida formalmente (Badel y Peña, 2010).

Según datos del Consejo Superior de la Judicatura publicados por Ámbito Jurídico (s. f.), a 31 de octubre de 2010 había en Colombia ochenta y ocho mil doscientas cuarenta (88.240) mujeres abogadas inscritas con tarjeta profesional vigente, frente a noventa y nueve mil cien (99.100) hombres abogados inscritos con tarjeta profesional vigente. Es decir que las mujeres abogadas son el $47.10 \%$ de las personas que ejercen esta profesión en Colombia.

Una primera mirada a las cifras genera la impresión de una historia de éxito y hace pensar que 
la pregunta por el lugar de las mujeres ha sido resuelta (Schultz, 2003a). No obstante, el crecimiento de la participación de las mujeres en todos los niveles de la educación y el mercado laboral choca con la persistencia de desigualdades en la posición que alcanzan mujeres y hombres en el mercado de trabajo (Arango, 2004, p. 444). ${ }^{1}$

Mirada de cerca, la discriminación hacia la mujer persiste aunque en formas más sutiles. Ocurre a menudo involuntariamente o bajo la convicción de que puede ser racionalmente justificada. Como lo señala Deborah Rhode (2003), las mujeres tienden a identificar actos de discriminación de forma mucho más clara que los hombres, sin embargo ambos sexos se inclinan a atribuirlos a fallas individuales antes que a cuestiones basadas en género.

En el ámbito profesional, las mujeres se enfrentan a retos que limitan sus posibilidades de acceso, éxito y permanencia. Barreras como los techos de cristal, paredes de cristal y puertas giratorias permiten comprender su discriminación en este ámbito desde distintas dimensiones.

Asociados a las barreras para el ascenso en la profesión, los techos de cristal son los obstáculos (informales pero institucionalizados) que impiden a las mujeres llegar a las esferas profesionales más altas y su promoción a cargos directivos (Wills, 2007). La posición de las abogadas colombianas en la rama judicial es un reflejo de este tipo de obstáculos.

1 Véase también Peña, Hoyos y Ñopo (2010).
En Colombia, para 1999, ni en la Corte Constitucional ni en la Corte Suprema de Justicia había una sola magistrada (Wills, 2007). En la actualidad, los hombres predominan en la posición de magistrados en las altas Cortes colombianas. Este patrón, según un estudio realizado en el 2010, tiende a reproducirse en los tribunales superiores de distrito judicial de la jurisdicción ordinaria (Dumez Arias, 2010, p. 258).

Las mujeres no solo encuentran dificultades para ascender en la profesión, sino que aún hoy tropiezan con barreras que se traducen en las denominadas paredes de cristal, expresión que hace alusión a la resistencia frente a la presencia femenina en áreas de práctica que se perciben como masculinas, es decir, en áreas que, por ejemplo, requieren formas de comportamiento más combativas.

Estas resistencias resultan en la segregación de las mujeres hacia áreas de práctica que se presume van en consonancia con capacidades y cualidades típicamente asociadas a ellas, por ejemplo, ser colaboradoras, amistosas u orientadas al diálogo (Gorman, 2005). Este problema no se agota en la polarización de las mujeres, sino que se asocia además al menor prestigio e ingresos, toda vez que estas áreas de especialización son menos valoradas (Kay y Hagan, 1995).

Aún más, los criterios funcionales concernientes al tipo de trabajo que los abogados hacen, también juegan un papel importante en la segregación de las mujeres; incluso al interior de las distintas áreas de práctica, las mujeres son 
relegadas a los asuntos de menos visibilidad, perfil e ingresos (Schultz, 2003a).

Entre los retos a los que se enfrentan las mujeres en la profesión se cuentan las responsabilidades familiares, a esto se refiere el concepto puertas giratorias. Este fenómeno explica que las mujeres dejan sus trabajos no por motivos profesionales, sino como respuesta a las dificultades relacionadas con el manejo del tiempo y la doble carga familia-trabajo (Schultz, 2003a).

La sobrecarga de trabajo que llevan las mujeres por la tradicional asociación entre feminidad y mundo doméstico que les imputa a las mujeres la responsabilidad de las tareas de reproducción en el hogar. La doble jornada implica que las mujeres salen a devengar un salario o si trabajan en la informalidad, a generar unos recursos para sus familias, y al regresar a casa, deben continuar trabajando, lavando, planchando, cocinando, mercando, limpiando (...) Sus jornadas de trabajo no son entonces de ocho horas, sino mucho más extensas y exigentes que las de los hombres (Wills, 2007).

En un estudio denominado "Mujer y movilidad social" economistas analizan la situación de la mujer en Colombia. Para hacerlo siguieron un enfoque de ciclo de vida de las personas y sus hogares, que les permitió identificar los momentos y dimensiones sociales en que se manifiestan las desigualdades asociadas al sexo para los individuos.

El estudio revela que "muchas de las desventajas que enfrentan las mujeres tienen que ver con la división de roles y negociaciones al in- terior del hogar" (Peña, et al., 2012, pág. 9), división tradicional que redunda en que las mujeres, aunque sobrepasan a los hombres en años de educación, enfrentan mayores dificultades para acceder a posibilidades de trabajo remunerado (Peña et al., 2012).

Aún más, las mujeres no solo trabajan más, sino que ganan menos, pues solo reciben retribución económica por su participación en el mercado laboral, mientras que otras actividades de cuidado no son valoradas en términos económicos. Según cifras del DANE, citadas en la mencionada investigación, para el 2011 durante una semana típica las mujeres dedicaban 32 horas a trabajos no remunerados y los hombres solo 13. Las mujeres dedican en promedio 40 horas al trabajo remunerado mientras que los hombres pueden dedicarle 48 horas. En suma, la jornada laboral de las mujeres sobrepasa a la de los hombres en 11 horas semanales (Peña et al., 2012).

La división sexual del trabajo, en virtud de la cual las tareas de crianza y cuidado, así como las responsabilidades domésticas continúan predominantemente en cabeza de las mujeres, no solo tiene efectos en su permanencia en el mercado laboral, sino en su imagen profesional y oportunidades de éxito. En el ejercicio profesional del derecho, la pobreza de tiempo de las mujeres riñe con la imagen de éxito de los abogados, que se mide por el tiempo invertido en el trabajo remunerado. En esta disciplina se sospecha que las mujeres y aún más las mujeres con hijos son menos ambiciosas 
y comprometidas con su profesión (Schultz, 2003a).

\section{B. La pregunta por la discriminación}

El considerable aumento en el número de mujeres ejerciendo el derecho, una profesión que antes les estaba vedada, no significa que la pregunta por ellas se encuentre resuelta. Como se ilustró, aún persisten patrones de discriminación que las mantienen en los márgenes del poder y que limitan sus oportunidades de éxito y permanencia en la profesión.

Para comprender lo que interviene en la discriminación de género en el campo profesional parto del marco interpretativo propuesto por Wills (2007). Según la autora, la exclusión y discriminación de las mujeres se ha sostenido sobre dos pilares fundamentales: 1. La prohibición de la presencia física de las mujeres en todos aquellos lugares considerados como constitutivos de lo público; 2. Estas interdicciones se sostuvieron y legitimaron sobre la base de ciertas representaciones, es decir, discursos, narrativas, expresiones culturales, historias acerca de lo femenino que adscribieron imperativamente a la mujer al ámbito doméstico.

Según Wills (2007), la exclusión se funda en la construcción cultural de diferencias que justifican el trato desigual. Estas construcciones culturales son producto de "visiones de mundo, prejuicios y sentidos comunes de larga data que, de tanto ser confundidos con la propia realidad terminaron naturalizando la exclusión" (pág. 37), y que no solo han creado los criterios para establecer fronteras entre incluidos y excluidos, sino que además legitimaron jerarquías entre los diferentes. Así, lo femenino no solo se concibe como lo distinto de lo masculino, sino también como lo opuesto inferior de lo masculino (pág. 38).

El dilema de la dominación cultural implícita en las definiciones de atributos distintos es que opera de manera que las diferencias construidas históricamente son naturalizadas y asumidas como inmodificables. Lo dramático de la dominación cultural es que no solo quienes construyen las representaciones de lo femenino inferior las viven como obvias e incuestionables, sino que además las mujeres terminamos por asumirlas como propias (Wills 2007).

Así las mujeres acaban sintiéndose, pensándose y actuando como seres esencialmente emocionales, y ese rasgo incorporado por ellas como innato, lo viven en el terreno público como algo negativo que las desmerita. Por esta razón, la dominación cultural termina atentando contra la autoestima y el amor propio de excluidos y excluidas, mecanismo que justamente los lleva a aceptar su subordinación como natural frente a estas circunstancias (Wills, 2007, pág. 51).

Bajo el entendido de que la discriminación de las mujeres es producto de dinámicas de exclusión, pero además de representaciones y narrativas, superarla requiere de su inclusión en lugares que antes les estaban prohibidos, pero más allá, precisa de una reparación de la devaluación cultural a la que fueron sometidas. Superar la discriminación de las mujeres 
requiere la posibilidad de reflexionar y significar tanto su identidad como sus intereses dentro de espacios en los que antes eran ajenas (Wills, 2007, pág. 46).

Pretender que existe neutralidad y simetría de poder donde no existe, le resta visibilidad a patrones persistentes de discriminación, genera autoaversión y deja a las mujeres en el dilema de tener que adaptarse a una cultura patriarcal y negar el género en un entorno que se los recuerda constantemente.

Este estudio, partiendo de la hipótesis de que el derecho es una disciplina con una cultura predominantemente masculina, se concentró en explorar desde una metodología cualitativa si las abogadas identificamos, o no, como discriminatorias prácticas que han sido señaladas como desventajosas para nosotras en el ámbito profesional. Además, a partir de los patrones de exclusión detectados, se hizo un esfuerzo por identificar intereses comunes para pensar en un proyecto de mujeres abogadas.

La pregunta por la discriminación en estos términos es pertinente e interesante, pues según la literatura estudiada la representación e influencia de las mujeres en la profesión ha recreado su problema de otra forma. El problema central contemporáneo es la negación de que, de hecho, existe un problema serio (Rhode, 2003). Parte del problema radica en definiciones restrictivas de lo que se entiende por discriminación (Rhode, 2003).
Los hallazgos de un estudio realizado en Estados Unidos mostraron que, para los abogados, sus lugares de trabajo reproducen ejemplos poco claros de discriminación. Aunque se identificaron supuestos degradantes, ofensas involuntarias, etiquetas condescendientes, estereotipos, preferencias no reconocidas y políticas de trabajo neutrales en la forma pero no en la práctica, estas situaciones no fueron detectadas como discriminación, en el entendido de que no conllevaban un perjuicio abierto e intencional (Rhode, 2003).

En este estudio se entenderá la discriminación de género en los términos establecidos en el artículo 1 de la Convención sobre la eliminación de todas las formas de discriminación contra la mujer (CEDAW), aprobada en Colombia por la Ley 51 de 1981 y que establece:

A los efectos de la presente Convención, la expresión "discriminación contra la mujer" denotará toda distinción, exclusión o restricción basada en el sexo que tenga por objeto o por resultado menoscabar o anular el reconocimiento, goce o ejercicio por la mujer, independientemente de su estado civil, de los derechos humanos y las libertades fundamentales en las esferas política, económica, social, cultural y civil o en cualquier otra esfera

\section{MARCO TEÓRICO}

Los estudios sobre las abogadas pueden clasificarse, a grandes rasgos, entre aquellos que abordan la inclusión, situación y permanencia de las mujeres en esta profesión, y los que se 
preguntan por el impacto que sobre la abogacía ha tenido el ingreso de un número tan significativo de mujeres. Dentro de este segundo grupo de estudios se incluyen aquellos que indagan por la posibilidad de que las mujeres ejerzan el derecho de una forma distinta a los hombres.

Los esfuerzos por abordar el tema de las mujeres en la práctica del derecho también pueden clasificarse según las preguntas de las que parten: 1. De un lado se encuentran los estudios que se preguntan ¿por qué? la entrada de las mujeres a la profesión fue tan tardía y renuente; 2. De otro, aquellos que se cuestionan sobre, ¿qué?, una vez dentro de la profesión, ha impedido su avance y el éxito profesional; 3. Por último, están aquellos que se ocupan de los cambios que el ingreso de las mujeres ha significado para la profesión. Este último tipo de estudios puede subdividirse en: Ios que se refieren a cambios en la estructura de la profesión, en términos de estatus, prestigio e ingresos, y los que examinan los cambios cualitativos relacionados con la posibilidad de que las mujeres introduzcan una "voz diferente" o una perspectiva distintiva al ejercicio del derecho.

\section{A. La entrada de las mujeres a la profesión}

Los estudios que se preguntan por el ingreso de las mujeres a la profesión parten de un lugar común en el que a las mujeres les fueron negados los derechos civiles y el acceso a la educación, sobre la creencia de que su naturaleza las hacía inadecuadas para la ley y la administración, al tiempo que las calificaba para un rol clave en la vida doméstica (Schultz, 2003a).
Ilustrativo de lo anterior es el famoso caso del siglo xIx Bradwell vs. Illinois (1873). Myra Bradwell Ilevó a la Corte de Illinois una solicitud para poder ejercer el derecho de conformidad con una ley estatal que permitía a cualquier adulto de buen carácter y con suficiente formación ser admitido. La Corte rechazó su solicitud indicando que las mujeres no contaban con la naturaleza para la práctica jurídica. Bradwell apeló la decisión ante el Tribunal Supremo de Estados Unidos, y aunque la mayoría no hizo ninguna referencia explícita al sexo, tres jueces afirmaron que la timidez natural y la delicadeza propia del sexo femenino, las incapacita para muchas de las ocupaciones de la vida civil (Fedler, 1994).

Para que las mujeres pudieran tener un lugar en la profesión, toda una serie de factores externos tuvieron que coincidir: 1 . Mejores oportunidades de educación, 2. Cambio cultural en la percepción de las mujeres y su potencial, 3. Apoyo de miembros del sexo masculino, 4. Apoyo de otras mujeres. Según lo expuesto por Schultz (2003a) fue el movimiento de mujeres y su lucha por los derechos civiles a finales del siglo xix, lo que les abrió el camino para elegir una carrera legal.

Aunado a lo anterior, la introducción de un sistema formal de calificaciones para acceder a la profesión y a puestos públicos, es decir, la profesionalización de las carreras, por oposición al sistema de apadrinamiento o pupilaje, permitió a las mujeres demostrar que eran perfectamente capaces de formarse como abogadas (Schultz, 2003a). 
En Colombia, para que las mujeres pudieran acceder a una formación legal tuvieron que ampliarse las oportunidades educativas. La Constitución de 1886 establecía en el artículo 38 que la religión católica, apostólica y romana era la de la nación. El Concordato firmado el 31 de diciembre de 1887, le otorgaba a la Iglesia católica la potestad de custodiar los contenidos difundidos en la escuela pública; además, le concedía poderes en la regulación del matrimonio y por esa vía poderes sobre la legislación civil y sobre la conducta de las mujeres (Wills, 2007).

De esta manera, aun cuando no existía una prohibición explícita para que las mujeres accedieran a la educación superior, se refrendaba un tipo de educación asociada a las tareas domésticas y a la crianza que les hacía imposible hacerlo. De acuerdo con Wills (2007), solo hasta 1932 con la elección de un gobierno liberal pudo establecerse un currículo igual para todos (decretos presidenciales n. ${ }^{\text {s }} 1874$ de 1932 y 227 de 1933).

En Colombia, la primera abogada fue Rosita Rojas Castro, quien obtuvo su título profesional en 1942 como doctora en Derecho y Ciencias Políticas de la Universidad Externado de Colombia.

\section{B. Avance, situación y permanencia de las mujeres en la profesión}

Este tipo de trabajos se concentran en explicar las diferencias de género en la profesión, a partir de dinámicas de exclusión y discriminación. Concretamente en el análisis de:

\section{Mecanismos de exclusión relacionados con la ausencia de las mujeres en los escalones más altos de la profesión}

Incluida la brecha en la autoridad y promoción del empleo (Bergallo, 2006), se preguntan por qué mujeres con la misma educación y experiencia que los hombres no son seleccionadas, en igual medida que ellos, para ocupar cargos de dirección y decisión (Kay y Hagan, 1995).

Estos estudios critican las teorías del capital humano y desvirtúan por medio de estudios empíricos la noción de que las diferencias experimentadas por hombres y mujeres en ingresos y posición son producto de diferencias en habilidad y experiencia. Según las teorías del capital humano, diferencias intrínsecas a nivel reproductivo entre los sexos se magnifican a través de diferencias de género en cuanto a las decisiones de invertir en las esferas separadas de carrera y hogar.

La teoría del capital humano asume que las inversiones de las mujeres en la familia inhiben su inversión en educación y experiencia, lo que hace que sean menos productivas, razón por la que las recompensas en posición e ingresos son obtenidas por los hombres que eligen invertir más fuertemente en capital humano (Kay y Hagan, 1995).

Los estudios que se concentran en explicar las diferencias de género en la profesión, dando cuenta de dinámicas de exclusión y discriminación, han establecido dos cosas: 
- Las mujeres obtienen menos retorno que los hombres por su dedicación, compromiso e inversión en educación y experiencia; enfatizan en la existencia de barreras estructurales que se concretan en restricciones institucionales, recompensas inadecuadas en términos de promoción laboral e ingresos para las mujeres que invierten tanto como los hombres en capital humano; estructuras jerárquicas de trabajo en las que las mujeres son excluidas del acceso a clientes y casos importantes, así como, a tutoría adecuada (Kay y Hagan, 1995).

- Existen, además, factores intangibles o restricciones culturales, porque para ascender en la profesión es necesario no solamente el capital humano obtenido a través de la educación y la experiencia, sino que se requiere también: a. capital social, es decir, conexiones sociales esenciales a la hora de atraer clientes; b. capital cultural, esto es, capacidad para participar en una cultura de estatus, entendida como un recurso que permite a sus actores obtener una ventaja al manejar impresiones y construir redes sociales esenciales para el éxito profesional.

El capital social y cultural necesario es más difícil de obtener para las mujeres, en un mercado de trabajo dominado por la cultura masculina. Existe un desajuste entre las características tradicionalmente asociadas a lo femenino y las asociadas con el éxito profesional. Este desajuste deja a las mujeres abogadas confrontadas con un continuo doble estándar: "Se las acusa por ser demasiado pasivas o demasiado fastidiosas, demasiado femeninas o no suficientemente femeninas. Lo que se considera asertivo en un hombre es abrasivo en una mujer" (Rhode, 2003, pág. 11).

\section{Movilidad profesional}

Estudios sobre la movilidad profesional de las mujeres han descubierto que si bien es mayor que la de los hombres, esta tiende a ser más hacia los lados o hacia abajo, que en ascenso, lo que las convierte en miembros transitorios de profesión. Esto se explica como resultado de la doble carga familia-trabajo (Rhode, 2003).

Según investigaciones realizadas por la socióloga y profesora Cynthia Fuchs Epstein en Estados Unidos, las dinámicas que disuaden a las mujeres de continuar en el ejercicio del derecho están relacionadas con estereotipos, actitudes tradicionales y comportamientos alrededor del papel de las mujeres como madres (New York City Bar [NYc], 2006), así como en la falla de sus compañeros hombres en adquirir responsabilidades en la familia y de sus colegas por no apoyar arreglos de trabajo alternativos (Rhode, 2003).

La doble presencia de las mujeres en el ámbito laboral y familiar hace que vivan en lo que Arango (2011) denomina “doble negación”, es decir, que cuando están en el trabajo se esfuerzan por actuar como si no tuvieran obligaciones domésticas y familiares para no ser estigmatizadas, y cuando están en la casa realizan las tareas de cuidado como si no tuvieran una jornada laboral que cumplir fuera del hogar.

\section{Polarización y segregación}

Este tipo de análisis se ocupa de la polarización y destinación de las mujeres hacia áreas menos 
visibles y prestigiosas de la profesión, así como su captación en tareas mecánicas y menos importantes como producto de estereotipos. Por ejemplo, bajo el entendido de que las mujeres tienen menor capacidad de decisión, son descalificadas para posiciones directivas en trabajos corporativos (Gorman, 2005).

Según estudio realizado por Elizabeth Gorman (2005), en el que analiza las dinámicas de contratación en las grandes firmas de abogados de Estados Unidos, cuando los criterios de selección están relacionados con características consideradas tradicionalmente masculinas (ambición, asertividad, habilidad empresarial, capacidad de decisión, energético, independencia, experticia, liderazgo, lógica, orientación cuantitativa, resuelto y confiado), las mujeres tienen menos posibilidades de ser contratadas, mientras que sus oportunidades mejoran cuando entre los criterios requeridos en el perfil se incluyen atributos considerados estereotípicamente femeninos (colaboración, accesible, amigable, amistoso, verbalmente orientado).

\section{Los cambios en la profesión por el ingreso de las mujeres}

Entre los estudios que se preguntan por los cambios producto de la introducción de las mujeres en la profesión pueden identificarse dos tipos: los que se refieren a cambios por la entrada masiva de mujeres a la profesión, en términos de estatus, prestigio e ingresos; y los que se preguntan por la posibilidad de que las mujeres introduzcan una "voz diferente" o una perspectiva distintiva en el ejercicio del derecho.

\section{Los cambios en estatus, prestigio e ingresos}

La pregunta por la posible pérdida de estatus del derecho como resultado del ingreso de importantes contingentes de mujeres parte de la asunción común de que la entrada de las mujeres a cualquier profesión conlleva el desprestigio de esta (Schultz, 2003b). Lo que subyace a este tipo de creencias es la idea de que las mujeres crean problemas y la tendencia a responsabilizarlas por situaciones consideradas poco satisfactorias (Boigeol, 2003).

\section{Los cambios cualitativos en la profesión}

Diversos estudios dentro de la corriente de la teoría feminista popularizada por Carol Gilligan se preguntan por la posibilidad de que las mujeres introduzcan al derecho una forma distintiva de ejercerlo. A este tipo de análisis subyacen las siguientes preguntas: ¿Son las mujeres esencialmente diferentes a los hombres? ¿Son las diferencias entre hombres y mujeres construidas socialmente?

La noción de que las mujeres puedan cambiar la profesión con su ingreso supone que son distintas a los hombres. Los feminismos culturales introducen la idea de que debido a los roles sociales y experiencias de vida diferenciadas, hombres y mujeres desarrollan tendencias morales diferentes. En su experiencia vital las mujeres acentúan valores como el cuidado, las características relacionales, la responsabilidad y el trabajo de nutrición (Bergallo, 2006). 
Los feminismos culturales al reivindicar características reconocidas como típicamente femeninas proponen la necesidad de incorporar la perspectiva y la voz femenina en campos como el derecho, impregnados de una visión masculina del mundo, que niega a las mujeres. No obstante, la otra cara de los feminismos culturales radica en que el reconocimiento de diferencias de género, en un contexto en que la opresión de las mujeres radica precisamente en que los atributos asociados a lo femenino son desvalorados, redunda en la existencia de una carga negativa de la diferencia.

La cultura masculina del derecho promueve un tipo de abogado correcto cuyas características son generalmente asociadas con atributos masculinos. En un contexto así, las mujeres estarían constantemente enfrentadas a la tensión entre rescatar una voz femenina y el prestigio profesional. Las mujeres, a través de la educación y la práctica legal, se verían sometidas a un proceso de aculturación que haría muy difícil el proyecto de incluir una voz propia en la profesión.

Las instituciones, y en particular el derecho, trasmiten a las mujeres expectativas específicas en cuanto a formas de expresión, conocimientos, habilidades, aspiraciones deseables, etc. (Bergallo, 2006). En esa medida, el derecho, al ser una profesión en la que predomina la perspectiva masculina, requeriría de las mujeres una adaptación al ambiente jurídico para ser exitosas (Schultz, 2003b).

El análisis sobre los cambios cualitativos que introducirían las mujeres a la profesión se divi- den entre aquellos encaminados a identificar la "voz diferente" o la perspectiva distintiva de las mujeres dentro de la práctica jurídica, y los que ponen en evidencia las dificultades inscritas en un proyecto femenino del derecho que pretenda encontrar y articular una voz propia de las mujeres.

Dentro del primer tipo de trabajos puede incluirse la obra de Carrie Menkel-Meadow (2013). A mediados de los 80 Menkel-Meadow aplicó las teorías de Gilligan al caso específico de las mujeres abogadas. La autora asume que sin importar su origen (bien sea biológico, político o social), las diferencias de género existen, y que mientras existan los trabajos sobre el tema deben tomar en consideración las experiencias de las mujeres.

Partiendo de la tesis de Gilligan, analiza los talentos de un hombre y una mujer para el ejercicio de la profesión jurídica, y la manera en que sus habilidades derivan de diferentes experiencias de vida. Según Menkel-Meadow las mujeres procurarían una resolución de conflictos que acentúe y valore más la conexión que la autonomía, privilegiando la mediación como alternativa al sistema adversarial (Kohen, 2008).

No obstante, la autora reconoce que las diferencias en el estilo y formas de razonamiento entre abogadas y abogados tienen consecuencias profundas en relación con la adaptación a sus roles profesionales; en ese orden, las mujeres frecuentemente enfrentan conflictos entre su moral personal y profesional (Kohen, 2008). 
En suma, Menkel-Meadow afirma que las mujeres introducirían un modelo alternativo de ejercer el derecho, “más cooperativo, contextual, menos atado a normas, con mayor capacidad de respuesta al otro, sensible a la justicia social y capaz de incorporar las concepciones femeninas de salud psicosocial y equidad familiar" (Kohen, 2008).

\section{Los dilemas del impacto cualitativo de las mujeres en la profesión}

Las principales críticas a los estudios sobre el impacto cualitativo de las mujeres en la profesión o la posibilidad de encontrar una voz distintiva de las mujeres provienen de la convicción de que sus experiencias e identidades no pueden ser homogeneizadas, y que la reivindicación de la diferencia puede ser cooptada por fuerzas conservadoras para justificar la asignación de roles femeninos tradicionales (Kohen, 2008).

Por esta razón, los estudios que aún se preguntan por el impacto cualitativo de las mujeres en el ejercicio del derecho reconocen ciertas diferencias entre los atributos considerados típicamente femeninos y típicamente masculinos, pero desde modelos explicativos más contextualizados, que enfatizan múltiples fuentes de identidad.

Esta clase de análisis ha registrado importantes permanencias. Para ascender en la profesión es necesario el capital humano obtenido a través de la educación y la experiencia, pero además el capital social y cultural que facilite la movilidad profesional. Este tipo de capital es de más difí- cil acceso para las mujeres, en tanto se fundamenta en un orden simbólico basado en redes y estilos de trabajo masculino, así como una fijación en el capital cultural de los hombres como opuesto al capital cultural de las mujeres.

En general, el capital social y cultural de las mujeres es menos valorado por varias razones: tienen menos contactos en redes masculinas; participan con menos facilidad en redes sociales masculinas (hablar de deportes, salir en las noches, salir a cenar, que se complica para mujeres con responsabilidades domésticas y de cuidado); el trato hacia las mujeres subraya sus estilos como débiles, poco asertivos y sin autoridad (Schultz, 2003a).

Incluso, las mujeres que han alcanzado los más altos niveles en la profesión, no cuentan con el mismo grado de poder de decisión, independencia o autoridad con el que cuenta un hombre en su posición. En general el sexo masculino ha sido una parte integral de la definición de las funciones de autoridad, como las ejercidas a través del derecho. El modelo tradicional de la profesión ha sido claramente masculino. Así como la autoridad dentro de la familia solía ser paterna, el juez en el derecho fue una figura que representaba la autoridad masculina (Boigeol, 2003).

Las mujeres, de manera inevitable, desafían una visión restrictiva de autoridad asociada a la fuerza y la presencia física, a la fuerza de la voz. Aunque las mujeres no necesitan gritar y golpear la mesa con el puño para afirmar su autoridad, sí necesitan mostrar completa maestría 
del tema, recordar de forma rigurosa los procedimientos y en general mostrar mayor pericia intelectual para compensar su falta de capital cultural masculino (Boigeol, 2003).

Bajo la percepción generalizada de que las mujeres son diferentes, son esperados cambios en su comportamiento. La adaptación y el cambio son parte de la socialización profesional tanto para hombres como mujeres. No obstante, en la medida en que las mujeres son percibidas como distintas (extranjeras a la cultura masculina del derecho) un mayor grado de cambio es esperado (Schultz, 2003a).

Las mujeres deben mostrar sus activos y habilidades de manera más explícita para compensar su falta de capital social y cultural; deben mostrar de manera más conspicua formas tangibles e intangibles de capital social y cultural. Esto se traduce en la habilidad de mostrar compromiso profesional y atraer clientes; en la aprobación, identificación y apoyo de metas e intereses relacionados con la práctica legal, además de formas de expresión, habilidades y conocimientos que se ajusten a lo que se espera del "abogado correcto". A las mujeres no solo se les exige asimilarse sino exceder las expectativas del abogado exitoso (Schultz, 2003a).

Según resultados de una investigación realizada en Canadá sobre la posibilidad de las mujeres para acceder a la posición de socias en firmas de abogados, existe un doble estándar para evaluar a hombres y mujeres. Mientras los hombres son valorados y recompensados por representar imágenes tradicionales de familia, se espera que las mujeres rompan las convenciones dándole prioridad al trabajo por fuera del hogar, así como la promoción de intereses relacionados con la práctica profesional, antes que con la academia o la reforma legal (Kay y Hagan, 1995).

Este doble estándar tiene dos consecuencias: 1. Refuerza estereotipos a propósito de los roles de las mujeres como madres, de manera que se sospecha que una mujer con hijos no estará dispuesta a desplegar el compromiso requerido, razón por la que deberá llevar casos o clientes de bajo nivel; 2 . Se espera que las mujeres demuestren mayor compromiso con la práctica jurídica, lo que resulta en un énfasis en temas cotidianos al darles prioridad sobre asuntos más amplios como la reforma de la profesión (Kay y Hagan, 1998).

Se espera que las mujeres permanezcan femeninas, pero al mismo tiempo existe la presión para asimilarse a comportamientos masculinos. Las mujeres no pueden ganar; cuando son exitosas en asimilarse demasiado bien a la cultura masculina, son acusadas por ser excesivamente duras. En palabras de Rhode (2003), lo que se considera asertivo en un hombre es abrasivo en una mujer.

La conclusión de este tipo de estudios es que las mujeres son sometidas a un proceso de aculturación que se completa cuando terminan su entrenamiento legal. Las mujeres son influenciadas en su comportamiento, en diferentes grados, dependiendo de su voluntad para adaptarse, la forma en que manejan la presión para ajustarse y el campo en que trabajan. 
Después de la aculturación, la motivación primaria de las mujeres es un sentido de obligación con su rol profesional que las incentiva a adaptarse a las normas existentes. Bajo estas circunstancias no es extraño que las mujeres estén más interesadas en adquirir una parte del poder y el prestigio de la profesión, que en la reforma de la profesión, desde la "voz de las mujeres" (Schultz, 2003a).

Otra de las dinámicas que según la literatura disponible interfiere con el proyecto de las mujeres abogadas es la negación. Existen diferentes explicaciones para dicho fenómeno. Un primer grupo sostiene que la resistencia de las mujeres a identificarse como víctimas es una estrategia de autoprotección.

Al respecto, Rhode (2003) sostiene que las mujeres pueden considerar demasiado costoso en términos de autoestima y eficacia identificarse como víctimas, así como pasar por la dificultad de identificar a los perpetradores, razón por la que preferirían revisar sus concepciones acerca de la culpa o el mérito. Otra hipótesis es que las mujeres no registran señales objetivas de discriminación de género porque nunca han tenido la vivencia de una existencia sin ellas (Kohen, 2008).

Otras subrayan que los valores masculinos prevalecientes promueven la conformidad y la falsa conciencia de las mujeres, dificultándoles la posibilidad de identificar sus experiencias laborales con discriminación de género. Las mujeres expresan más bien gratitud por ser admitidas en ámbitos masculinos y por ello obvian quejas y críticas sobre su situación.
Finalmente, un tercer grupo, inspirado en el concepto de subjetividad de Bordieu, identifica las dinámicas de negación en ámbitos caracterizados por una supremacía masculina "como una práctica discursiva; el acontecer de una interiorización corporal y mental de múltiples situaciones sociales dentro de un proceso continuo de formación de identidades" (Kohen, 2008, pág. 187).

\section{MARCO METODOLÓGICO}

Este estudio se pregunta por el impacto de género en el ejercicio profesional de las mujeres abogadas, y más concretamente por la discriminación de género en la práctica del derecho en el sector público, en Bogotá. La investigación parte de la hipótesis que las mujeres abogadas no identifican la discriminación ni el impacto del género en el ejercicio profesional, porque al hacerlo corren el riesgo de perder relevancia y legitimidad para alcanzar respeto y prestigio dentro de una profesión tradicionalmente masculina, en la que existen redes y estilos de trabajo masculinos. Las abogadas debemos, para ser exitosas, asimilar nuestros intereses a los de la cultura jurídica tradicional. Esto explicaría lo difícil que es introducir discursos sensibles al género en la práctica profesional.

\section{A. Delimitación del campo de investigación}

El trabajo de campo se propuso examinar estas percepciones en abogadas que estuvieran ejerciendo o ejercieron en el sector público bajo 
cualquiera de las modalidades de vinculación que este mercado ofrece (carrera administrativa, provisional, libre nombramiento y remoción o contratistas). Los motivos para elegir este mercado o campo fueron dos: de un lado sus particularidades y de otro el acceso a la información en atención a la preexistencia de una red de sujetos.

Según la revisión documental realizada, la administración pública ofrece varias ventajas significativas para las mujeres, entre ellas la protección de las madres trabajadoras, licencias de maternidad menos problemáticas y estresantes, oportunidades profesionales, remuneración neutral al género, mayores posibilidades de combinar la vida profesional y familiar, posición relativamente elevada, carga de trabajo manejable y menor presión competitiva (Schultz, 2003a).

Kay y Hagan (1995) caracterizan el contexto de los empleados del gobierno como único, puesto que su rendimiento no es evaluado respecto a reglas relacionadas con el lucro. Evidencia de lo anterior es que según estudio realizado en el 2010, las abogadas vinculadas mediante contrato de trabajo a la administración pública nacional, central y descentralizada superan en 14 puntos porcentuales a los hombres (Victoria Russi, 2010).

Se consideró que estas particularidades permitirían pasar de expresiones suficientemente documentadas de discriminación a través de cifras, como las referentes a la brecha salarial y la pobreza de tiempo de las mujeres, a otras formas de exclusión relacionadas con el capital social y cultural de estas (Gabel, 1967).

En general, la existencia de estas características distintivas del sector público, en relación con la idea de lucro y servicio, fueron confirmadas durante el trabajo de campo. Al respecto varias de las participantes afirmaron que la diferencia entre el sector público y el privado consistía precisamente en que mientras en el privado lo importante era generar un excedente o capital, en el sector público el objetivo era la satisfacción del interés general. Una de las entrevistadas afirmó:

Sí. Un poco, sí es diferente. Porque en el sector privado en términos generales, digamos, hay que ser un poco más competitivos. Si tú no produces, hombre o mujer, si no produces para la empresa sencillamente estás afuera ¿sí?, porque ese es un medio esencialmente capitalista en donde el término o el objetivo general es la ganancia o el excedente de empresa privada. De otra manera no te sostienes en el mercado. Mientras que en el sector público en principio el objetivo es de servicio, entonces está un poco más, es un poco menos hostil, llamémoslo así. (Entrevista, 28 de marzo de 2012).

Otra de las participantes expresó que las particularidades del sector público son claras:

Pues, claramente, porque cuando usted está en el sector privado usted está defendiendo el interés del privado y se está enfrentando al Estado. Y cuando usted está en el sector del Estado usted está es defendiendo el Estado, el interés común y la idea de comunidad, de solidaridad, de interés general versus un par- 
ticular que pretende, digamos, hacer valer su interés individual. (Entrevista, 01 de marzo de 2012).

Además hicieron afirmaciones como las siguientes: "Yo siento que es diferente. También hay un tema del horario, es muy diferente (...) Y hay más garantías laborales. No te van a salir con que "uy, se acabó la plata" porque pues uno sabe que no se acabó"; "sí hay más estabilidad en el sector público. Sobretodo pues estando en carrera administrativa como lo estoy, sí hay más estabilidad". (Entrevista, 06 de marzo de 2012).

El otro motivo para elegir el sector público fue el acceso a la información en atención a la preexistencia de una red de sujetos. El acceso inicial es determinante pues muchos proyectos de investigación surgen de membresías a ciertos grupos, de experimentar un tema en la vida real, y la academia puede proveer la motivación para el trabajo de campo (Crang y Cook, 2007).

\section{B. La entrevista}

La recolección de datos se realizó a través de entrevistas semiestructuradas que giraron alrededor de tres grandes temas: 1. Discriminación de género en el ejercicio profesional; 2. Percepción del derecho como una profesión tradicionalmente masculina, con un estilo, cuerpo de conocimientos, habilidades y formas de expresión específicas; y 3. Percepción sobre la importancia del género como variable social. Para evitar sesgos y permitir que las participantes reflexionaran sobre su posición en la profesión, no se mencionó la palabra discriminación o ex- clusión en las preguntas de la entrevista, sino se habló en términos de retos profesionales, aspiraciones profesionales y percepción sobre el éxito profesional.

Para sortear en la mejor medida posible las dificultades relacionadas con el lenguaje, se estructuró la entrevista de manera que se preguntó primero por lo que cada entrevistada entendía como reto, éxito, estilos de trabajo. Partiendo de un significado común se profundizaba en el tema.

Respecto a la percepción del derecho como una profesión tradicionalmente masculina se les preguntó a las participantes por las características del abogado ideal, estilos de trabajo, habilidades e imagen profesional. Además se plantearon preguntas sobre características consideradas importantes para el ascenso y promoción profesional. En cuanto a la percepción sobre el género y la posibilidad de introducir discursos sensibles a dicho aspecto se preguntó por la conformación de sus equipos de trabajo, así como por su interés y expectativas en cuanto a la creación de redes de trabajo y apoyo femeninas.

\section{La muestra}

Como mencioné, este estudio no pretende medir o realizar generalizaciones, sino explorar las percepciones sobre discriminación profesional, desde la experiencia de quienes están potencialmente expuestas a ella. Lo importante al abordar a las entrevistadas fue la calidad y posición de la información que podían ofrecer. 
Las entrevistas se realizaron entre febrero y marzo del 2012, a diecisiete mujeres que ejercieron o ejercían como abogadas en el sector público al momento de la entrevista. De las diecisiete participantes, catorce ocupaban cargos de planta y las tres que no se encontraban ejerciendo en ese momento en el sector público habían ocupado cargos directivos en la administración.

Las participantes se encontraban en un rango de edad entre los 26 y 51 años. La mayoría de mujeres entrevistadas mayores de 31 años eran madres; en total, de las diecisiete participantes, ocho tienen hijos. Ninguna de las participantes en el rango de edad por debajo de los 31 años tiene hijos. En cuanto a su estado civil, tres son casadas, dos se encuentran en unión marital de hecho, una está separada y otra está divorciada. Las otras diez son solteras.

En el consentimiento informado para participar en la investigación se garantizó la confidencialidad y el anonimato de la información, por esta razón no se revela la identidad de las entrevistas. Esto no le resta valor o rigurosidad a la investigación, porque más allá del argumento de autoridad lo importante en este trabajo era conocer las percepciones de personas situadas en un contexto específico.

\section{Análisis de resultados}

\section{Percepción sobre la discriminación en la profesión}

De las diecisiete abogadas entrevistadas, cuatro expresaron explícitamente haber experimen- tado alguna forma de discriminación por cuestiones de género. El resto se pueden clasificar, de una parte, como aquellas que identifican dinámicas de distinción, exclusión o restricción basada en género pero no las perciben expresamente como discriminación, y de otro, quienes perciben menos el impacto de género en el ejercicio profesional.

Quienes no percibieron el impacto de género lo explicaron en razón de dinámicas relacionadas con factores de clase que resultaron más determinantes en sus reflexiones o porque se sentían satisfechas con las oportunidades profesionales que han tenido. Una de las participantes identificó la discriminación laboral de las mujeres como una realidad que debía ser explorada, pero no expresó haber experimentado ningún tipo de situación discriminatoria por razones de género en la propia práctica profesional.

De las diecisiete participantes, doce refirieron alguna percepción de dificultad, restricción o exclusión. Estas percepciones estuvieron en su mayoría relacionadas con la doble carga familiatrabajo y con estereotipos sobre la falta de compromiso y capacidad de las mujeres con fundamento en una maternidad actual o potencial.

Incluso la participante más enfática en negar el impacto de género en la profesión expresó:

Lo que de pronto sí creo que influye es el hecho de tener hijos, porque de entrada el empleador o el jefe tienen la percepción de que esa profesional no va a contar con el tiempo suficiente para dedicarle a su trabajo en caso de que se requieran unas jornadas arduas. Porque sabe 
que siendo madre de unos hijos va a preferir atender a sus hijos que quedarse a atender un asunto de trabajo. (Entrevista, 02 de marzo de 2012).

Las situaciones de distinción, exclusión o restricción descritas por las participantes fueron, a grandes rasgos, las siguientes: 1 . Sesgos relacionados con la apariencia. Al respecto expresaron que existe un entorno hostil al género, que consiste en descalificar a una abogada por bruta, si es bonita; 2. Sesgos y estereotipos relacionados con la maternidad; 3. Sesgos sobre la capacidad de decisión de las mujeres; 4. Persistencia de techos de cristal; 5. Persistencia de paredes de cristal; 6. Falta de capital social y cultural; 7. Barreras de acceso.

La dificultad en la que más se detuvieron fue en los sesgos y estereotipos relacionados con la maternidad. Sobre las dificultades que surgen al tratar de equilibrar las responsabilidades familiares y de cuidado con las profesionales manifestaron:

Lo mismo, porque cuando tú tienes una carga adicional que es ser mamá y esposa te pone como un título ya en la profesión. ¡Ah! Que esta mujer no le puede dedicar el $100 \%$ al trabajo. No, ya tiene uno una limitante de por sí. Yo tengo ese trauma porque me pasó tres veces y me lo dijeron así, de frente. Entonces por eso. (Entrevista del 08 de marzo de 2012).

También observaron que no solo mujeres que son madres se ven afectadas por los estereotipos construidos en torno a la maternidad. Participantes solteras y sin hijos reportaron que en entrevistas de trabajo percibían un sesgo hacia la maternidad, que expresaron en los siguientes términos:

Tristemente sí. Tristemente sí porque por ejemplo con el tema de la maternidad. O sea, yo por ejemplo estuve en una entrevista donde una de las preguntas que me hicieron fue si yo tenía intereses de tener hijos en el corto plazo. Entonces, pues ahí claramente... Digamos, aunque sea soterrada como la intención detrás de la pregunta pues es clarísima y es diferente. A un hombre no le hacen esa pregunta, por ejemplo. (Entrevista del 05 de marzo de 2012)

Otra participante afirmó:

Pues en cualquier ámbito siempre es más difícil para la mujer sobresalir y más en un ámbito laboral. En alguna oportunidad estuve postulada a un cargo y lo primero que me preguntaron era si era casada, si tenía hijos y si tenía disponibilidad de tiempo completo. El [empleador] primero partía de ahí, si podía tener o no espacio. (Entrevista del 02 de marzo de 2012).

De otra parte, la maternidad y el matrimonio son experimentados como incompatibles con el ascenso profesional y las posibilidades de adquirir recursos de capital humano. A propósito de esto una de las participantes expresó:

Yo creo que me he estancado. Desde hace un tiempo me he estancado. Porque ahí sí, yo creo que la mujer se estanca más que el hombre porque la mujer tiene que desempeñarse a nivel familiar de una forma completa. 0 sea, uno no puede dejar de atender los hijos por atender la oficina. (Entrevista del 01 de marzo de 2012). 
Sobre la capacidad y decisión de las mujeres, una de las participantes manifestó haber enfrentado discriminación en el sector defensa, en el que por ser esencial y naturalmente masculino existía la creencia de que las mujeres no eran capaces de adoptar los retos que el desempeño profesional en esa área requería. (Entrevista del 28 de marzo de 2012).

Otra participante manifestó que no existe confianza en la autoridad de las mujeres. Esto lo expresó en los siguientes términos:

Yo sí veo que hay como un miedo de darles las cosas a las mujeres, sienten que los hombres van a poder con cosas más como visuales, de televisión, que los pueden poner como para mostrarlos. Que las mujeres tal vez sí pueden hacer el trabajo pero como si uno se fuera a asustar, pues esa es mi percepción. Que sienten que uno se va a asustar. (Entrevista del 29 de febrero del 2012).

A propósito de lo que es necesario para el ascenso y la promoción profesional una de las abogadas mencionó:

Para un hombre puede ser más fácil ascender sin necesidad de tener igual nivel académico que la mujer, porque tienen una mayor habilidad para hacer el tipo de contactos necesarios para lograr un ascenso y brindar un mayor nivel de confiabilidad. (Entrevista del 26 de marzo de 2012).

Una participante describió las barreras a las que se enfrentó como estudiante de Derecho en la década de 1980:
Lo que pasa es que yo estoy hablando de una época de los años ochenta que fueron muy difíciles para las mujeres que queríamos como estudiar y solas hacer los caminos ¿si ves? Entonces era una cantidad de circunstancias adversas. No encontraba uno la libertad que tiene ahorita de conseguir un dinero e irme me matriculo y ya. Porque la mujer era para el hogar. La que lograra salir de ese campo pues era una cosa excepcional. Yo te digo, de sesenta personas que terminamos bachillerato en cuatro cursos de un colegio, si te digo tres logramos ser profesionales, tres o cuatro. (Entrevista del 06 de marzo de 2012).

\section{Respuesta a circunstancias de discriminación, exclusión o restricción}

Durante las entrevistas se trató de profundizar en dinámicas que pudieran ser significadas como modos de exclusión o discriminación, y en la medida de lo posible, por la posición de las participantes frente a este tipo de dinámicas.

Las respuestas de las participantes pueden clasificarse así: 1. Apuesta por sumar en formas tradicionales de capital humano como educación y experiencia para compensar dinámicas de exclusión o discriminación; 2. Resignación y adaptación; 3. Percepción de que las oportunidades son limitadas, lo que se traduce en satisfacción profesional a pesar de las dificultades.

Las que apuestan por formas tradicionales de capital humano parten de la confianza en el mérito y esfuerzo individual. Frente a restricciones y exclusiones, deben empeñarse en exhibir capacidades intelectuales superiores. Por ejemplo, 
una de las participantes al verse confrontada al estereotipo de falta de capacidad para desempeñarse en un área tradicionalmente masculina, se concentró en capacitarse e investigar a profundidad para sentirse segura al momento de opinar.

La apuesta por formas tradicionales de capital humano para compensar la falta de capital cultural masculino y participar adecuadamente en ambientes masculinizados fue una de las más comunes. Apostarle al capital humano les da un sentido de control sobre la situación. Reevaluar su concepción sobre culpa o mérito es más fácil que reconocer que existen sesgos en el ejercicio profesional.

La necesidad de acentuar los recursos de capital humano se traduce, según una participante, en mayores exigencias profesionales para las abogadas:

Entonces las mujeres tienen que ser doblemente hábiles, tienen que demostrar que son buenas y realmente serlo. Los hombres pueden pasar y colarse muy fácilmente; (...) hay ideas de que la mujer tiene que demostrar mucho más y demostrar doble trabajo para que sea reconocida, para que pueda ascender. (Entrevista del 20 de febrero de 2012).

La percepción de que las mujeres abogadas deben esforzarse el doble para posicionarse en la profesión fue puesta por otra participante en estas palabras:

Lo que pasa es que más allá del trabajo jurídico que uno desarrolla sí es un tema de que la mujer tiene que esforzarse más por ganar credibilidad. Entonces una mujer se demora mucho más tiempo en que sus ideas sean escuchadas, en que sean valoradas. A un hombre le queda mucho más fácil esa tarea por su presencia, por como lo perciben. En cambio las mujeres, digamos así, arrancamos más de abajo para lograr ser percibidas como inteligentes, valiosas, eficientes; como que es un trabajo mucho más duro posicionarse. En cambio el hombre sí siento que tiene ganado mucho más terreno para posicionarse fácilmente. (Entrevista del 01 de marzo de 2012).

La apuesta por la resignación y la adaptación fue más común en las participantes con más responsabilidades de cuidado. Para una de ellas, la idea de que las mujeres con hijos son menos comprometidas debería cambiar en términos generales, pero como no existen políticas ni incentivos para que el trabajo de las mujeres se valore igual, hay que resignarse a ser percibidas como poco profesionales por no poder asumir horas extra de trabajo. (Entrevista del 28 de marzo de 2012).

Frente a la doble carga familia-trabajo, la opción por la resignación y la adaptación se manifiesta en la idea de que quien debe asumir las dificultades que representa es la mujer, adaptándose y cumpliendo como mejor pueda con las múltiples responsabilidades y roles que ser mujer implica. A la pregunta sobre la existencia de retos diferenciados entre hombres y mujeres en el ejercicio profesional una participante contestó: "Son diferentes en cuanto a que uno de mujer tiene además el reto de ser mamá, de ser esposa, de ser hija. Entonces, el dirigir una casa 
tiene una carga más que la de los hombres". (Entrevista del 6 de marzo de 2012).

La misma participante expresó que, en su caso, ha sacrificado la posibilidad de continuar estudiando y el avance profesional, por la seguridad laboral y por horarios fijos:

Yo en este momento, por ejemplo, quisiera estudiar, hacer una maestría, seguir estudiando. Pero no tengo el tiempo porque tengo dos hijos pequeños, entonces no alcanzo. Prefiero en este momento dedicarle el cien por ciento a mis hijos y más adelante pues poder estudiar. Lo mismo a nivel profesional. Yo quisiera cambiar de entidad, quisiera tener otros retos y hacer otras cosas diferentes. Pero entonces en este momento la seguridad del trabajo y la comodidad del espacio y del tiempo que tengo son importantes para mí. (Entrevista del 06 de marzo de 2012).

Además de la resignación frente a la doble carga familia-trabajo, la necesidad de adaptarse se asoció con el imperativo de proyectar una imagen profesional determinada. Una de las participantes mencionó que una de sus prioridades como profesional era proyectar confianza y rigurosidad en el trabajo, hacer las cosas de cierto modo. Observó que dar el nivel de confianza que el éxito profesional requiere es más difícil para una mujer, porque se percibe que las mujeres hablan demasiado. (Entrevista del 16 de marzo de 2012).

Dos participantes, a pesar de las dificultades que identificaron, manifestaron estar satisfechas con su desarrollo profesional. Satisfacción producto de una negociación entre sus aspiraciones y las oportunidades que habían tenido. Una de ellas respondió:

Nunca me hubiera imaginado en este punto, digamos estar dónde estoy. Ha sido más que todo sorprendente. Obviamente ya cuando uno está en este punto pues lo único que quiere es seguir progresando en el tema de gerencia pública y de gestión pública. (Entrevista del 01 de marzo de 2012).

\section{Percepciones sobre la existencia de una cultura masculina del derecho}

Para determinar las percepciones sobre la cultura masculina del derecho se estableció si las participantes identificaban características diferenciadas en el ejercicio profesional de hombres y mujeres y si las de los hombres eran privilegiadas sobre las de las mujeres. De las diecisiete mujeres entrevistadas, quince señaIaron que existen diferencias explícitas en el ejercicio profesional entre hombres y mujeres, bien sea en términos de habilidades o de estilos de trabajo.

Para las participantes estas diferencias tenían distintas razones de ser: 1 . Son producto de construcciones sociales; 2. Están asociadas a una idea de "comportamiento natural"; 3. Son producto de un doble estándar.

Quienes se refirieron a estas diferencias en términos de construcción social, expresaron que experimentaban una ruptura entre las características asociadas a lo femenino y las caracte- 
rísticas propias como personas. Al respecto una participante dijo:

Yo creo que a uno sí le queda bastante metido en la cabeza el concepto que le meten a uno en la casa ¿no? Por ejemplo, a mí toda la vida mi mamá me decía, usted tiene que ser más dulce, tiene que ser más noble, como más obediente, más sumisa y yo siempre he sido todo lo contrario ¿sí?, pero entonces a veces uno se conflictúa en una situación ¿será que sí yo debo ser? Pero es mucho como el modelo que le meten a uno... (Entrevista del 28 de marzo de 2012).

Para otra de las entrevistadas, las diferencias entre hombres y mujeres son naturales:

Es que en realidad las mujeres tenemos unas cualidades que los hombres no necesariamente tienen, y viceversa. O sea, ellos tienen unas cualidades que nosotras no tenemos. Pero no es una obligación de tener qué sino de que, pues así son las cosas. (Entrevista del 01 de marzo de 2012).

Una tercera advirtió las diferencias en habilidades o estilos de trabajo entre hombres y mujeres como producto de un doble estándar. A propósito de esto afirmo:

Una mujer fuerte se ve como mala, como poco femenina, y cuando está siendo femenina entonces es mala en su trabajo. Es complicado, porque es como si no supieran qué quieren, en cambio en el caso de los hombres ¡Bien! Que hable duro, que pelee, que sea aguerrido, como ay sí, que grite en la mitad del salón les parece mágico. Pero una mujer que grita en la mitad del salón está loca o menopáusica o con la regla, yo no sé. (Entrevista del 29 de marzo de 2012).

A grandes rasgos, las diferencias en habilidades y estilos observadas por las participantes fueron las siguientes: las mujeres son más competitivas a nivel personal, los hombres lo son a nivel profesional. Mientras en una entrevista de trabajo las mujeres hablan más de sus cualidades personales, los hombres se refieren a sus competencias (entrevista del 28 de marzo de 2012). Las mujeres son más viscerales, se toman las cosas en un nivel personal y permiten que asuntos de índole privada se interpongan en el logro de sus objetivos.

Las participantes señalaron que las mujeres son más organizadas pues su rol en el hogar las obliga a ello (entrevista del 06 de marzo de 2012), son más rigurosas, meticulosas, transparentes, honestas, trabajadoras, comprometidas y responsables. Los hombres son más relajados y tranquilos, con mejores habilidades para manejar el estrés, razón por la que los prefieren para cargos de autoridad y poder (entrevista del 28 de marzo de 2012).

Las participantes en esta investigación identificaron claras diferencias en cuanto a las formas de expresión e imagen que proyectan mujeres y hombres abogados. Mientras los hombres se expresan en términos más técnicos, concretos y despliegan mayor conocimiento de la norma, las mujeres son más descriptivas y dispersas al expresarse (entrevista del 26 de marzo de 2012). A los hombres los eligen más para presentarse en audiencias, porque hablan fuerte, saben ex- 
presar y proyectar seguridad en el tono de la voz (entrevista del 29 de febrero de 2012). En términos generales, ellas consideraron que existe la percepción de que los hombres saben más.

Contrastando las características reseñadas por las participantes como típicamente masculinas y femeninas, con los rasgos o cualidades que asociaron al éxito profesional, se evidencia que en la profesión legal existe una cultura, es decir, una serie de formas de expresión, valores y cuerpos de conocimientos que son la norma y que se asocian con atributos masculinos.

En ese sentido, las participantes manifestaron que una profesional exitosa debe reflejar confianza, seguridad, mostrar capacidades intelectuales a través de conceptos bien estructurados, explicados y fundamentados (entrevista del 28 de marzo de 2012); proyectar conocimiento y usar un lenguaje técnico al expresarse (entrevista del 06 de marzo de 2012); hablar fuerte, claro, coherente, de manera razonable, desapasionada (entrevista del 06 de marzo de 2012); debe ser pausada, ecuánime, seria, mesurada, equilibrada, dueña de sí, armónica (entrevista del 26 de marzo de 2012); proyectar una imagen de estatus, elegancia y feminidad (entrevista del 01 de marzo de 2012).

Mientras las mujeres son percibidas como seres emocionales que se toman todo demasiado personal, la abogada exitosa debe ser equilibrada y mesurada, expresarse según parámetros tradicionales de autoridad, hablando fuerte y claro, usando el lenguaje técnico de la profesión. A partir de este contraste es posible plantear que las participantes en el estudio perciben la práctica profesional en el derecho como un espacio saturado de una serie de normas, actitudes y valores asociados a lo masculino, en el que las características de lo femenino conllevan un componente negativo.

No obstante, en lugar de obstáculos, las exigencias en términos de expresión e imagen claramente masculinizados son vistas como neutrales del ejercicio profesional. Como si no articularan suficientemente la noción de un capital cultural y social eminentemente masculino con la explicación de sus experiencias de devaluación cultural cotidianas.

Así, por ejemplo, una de las entrevistadas fue bastante enfática en señalar que la existencia de sesgos respecto a la capacidad de las mujeres para proyectar seguridad en cargos públicos hace que les cueste más trabajo posicionarse en cargos directivos, pero a la hora de establecer qué es lo determinante para la promoción profesional se refirió únicamente a títulos de educación y experiencia específica. (Entrevista del 28 de marzo de 2012).

\section{Sensibilidad al género como variable social relevante}

El género es una categoría social como lo es la raza o la clase. Esta investigación se propuso, entre otras cosas, explorar cómo perciben las mujeres que participaron en la investigación el impacto del género como variable social en su ejercicio profesional. La hipótesis planteada propone que las mujeres no identifican el impacto 
del género en el ejercicio profesional y que no reconocen intereses intelectuales, profesionales y sociales diferentes a los de la cultura masculina del derecho, porque en la profesión esto no es considerado como relevante ni legítimo.

Para indagar por la sensibilidad al género como variable social relevante, a las participantes se les preguntó por su conocimiento sobre políticas o programas dirigidos a problemáticas de género en las entidades en las que se han desempeñado como abogadas. Así mismo, se indagó por la importancia y pertinencia que atribuían a este tipo de medidas. De las diecisiete abogadas entrevistadas, ocho expresaron que conocían alguna política dirigida a abordar problemáticas de género, y doce las valoraron como importantes.

Quienes expresaron que políticas e iniciativas en este sentido no eran pertinentes, argumentaron que no eran necesarias o que sus consecuencias no resultaban ser las esperadas. Las participantes que se inclinaron por el primer argumento lo hicieron en estos términos: "Pues porque no entiendo para qué una entidad debería meterse en un tema de género si esa no es su misión, ni su función". (Entrevista del 01 de marzo de 2012).

Aquellas que se inclinaron porque las consecuencias de estas políticas no eran las esperadas, expresaron:

Eh... no sé. Es una pregunta difícil, con la que quizá no esté de acuerdo, porque tengo como un sesgo de cómo terminan operando esas políticas. $Y$ esas políticas terminan operando como las que uno ve en las comisarías de fami- lia o en las fiscalías en afiches: "la mujer tiene derechos" y terminan siendo como un discurso retórico, como una estrategia retórica pero en el fondo no cambian estas relaciones de poder. Creo que ese tipo de políticas, digamos, como afirmativas tiendo como a desconfiar. (Entrevista del 06 de marzo de 2012).

Adicionalmente, se les preguntó acerca de su conocimiento de espacios formales en los que las mujeres abogadas puedan compartir sus experiencias, preocupaciones, etc. Seguido se preguntó si consideraban importante que se generaran ese tipo de espacios. De las diecisiete participantes, solo una expresó conocerlos.

Catorce de las diecisiete participantes manifestaron que sería importante crearlos, con fundamento en argumentos que se pueden clasificar en tres tipos: 1. Como espacios necesarios para compartir vivencias comunes, encarar experiencias de discriminación y dificultades relacionadas con la doble carga familia-trabajo; 2. Como espacios para crear redes de apoyo y empoderar a las mujeres; 3. Desde el punto de vista profesional como un espacio para acceder a recursos de capital humano que no se pueden obtener de otra forma por falta de tiempo u otras dificultades.

Aunque las participantes manifestaron interés en la creación de espacios propios de mujeres abogadas para darle significado a su experiencia en la profesión, empoderarse y generar recursos de capital humano que les permitan compensar las desventajas de la doble carga familia-trabajo, algunas se mostraron a la vez escépticas frente a la posibilidad de que estos 
cumplan con los propósitos mencionados. Sobre esto opinaron:

Yo creo que no es muy fácil que ese espacio tenga como unos resultados buenos como a corto plazo porque las mujeres somos más como de mostrar todo lo que hacemos bien y no nuestros fracasos. (...) Entonces no sé hasta qué punto. Sería contar con un grupo de mujeres que fueran lo suficientemente sinceras y transparentes para que realmente sea enriquecedor. 0 si no va a ser es una vitrina de trofeos. (Entrevista del 28 de marzo de 2012).

Otras mencionaron el tema de la "solidaridad de género", y expresaron: “Eso no existe, al contrario, hay depredación de género" (entrevista del 28 de marzo de 2012); otra participante agregó que no existe, y hay una tendencia a unirse a la causa del machismo:

Pues no ha habido digamos aquí que yo conozca como muchas mujeres que se caractericen y que digamos, que mostremos nuestra parte femenina para decir, mire es que nos vamos por este lado, mire es solidaridad de género o esto, no. Sino al contrario, hay una tendencia más a unirse a la causa del machismo que a salvar digamos a toda la tendencia feminista o de género. (Entrevista del 02 de marzo de 2012).

Otra habló sobre la falta de solidaridad de género con relación a las tareas de cuidado y la doble carga familia-trabajo, en los siguientes términos:

No. No, yo creo que más comprensivo es un hombre. Los hombres son más respetuosos frente a la condición de ser mujer. Los hombres pueden ser más generosos y más com- prensivos frente a una enfermedad de un hijo, frente a citas médicas. Por su misma condición de respeto y como de condescendencia con las mujeres. La mayoría de hombres son más respetuosos frente a eso. Las mujeres que son mamás o que habían pasado por toda esa situación son como más berraquitas y exigen un poquito más. Entonces no son tan tranquilas frente a eso. (Entrevista del 02 de marzo de 2012).

Si bien las mujeres entrevistadas comprenden el género como una variable social relevante y reconocen la necesidad de medidas y espacios para abordar cuestiones asociadas a este, hacen la reflexión desde posiciones individuales y se muestran escépticas frente a la posibilidad de un proyecto de grupo.

\section{CONCLUSIONES}

El propósito de esta investigación consistió en explorar si las mujeres abogadas experimentaban, o no, dinámicas de exclusión y cómo las confrontaban. Partiendo de la pregunta por la discriminación se proyectó la posibilidad de identificar intereses comunes a partir de patrones persistentes de exclusión, con la intención de indagar sobre la probabilidad de construir un proyecto de las mujeres juristas desde un compromiso con la necesidad de asegurar un ejercicio profesional en el que no se reproduzcan dinámicas de distinción, exclusión o restricción.

Con el objetivo de explorar y comprender la situación objeto de estudio se realizaron entrevistas semiestructuradas en las que se indagó 
sobre la percepción de las participantes acerca de tres temas: 1. Discriminación de género en el ejercicio profesional, 2. Percepción del derecho como una profesión tradicionalmente masculina, con un estilo, cuerpo de conocimientos, habilidades y formas de expresión específicas; 3. Percepción sobre la importancia del género como variable social.

A partir del análisis de datos puede concluirse:

1. A propósito de la discriminación de género en el ejercicio profesional: las participantes identifican diversas dinámicas consideradas desventajosas. Perciben en las causas de estas dinámicas desventajosas factores externos fuera de su control, sin embargo para contrarrestarlas invierten en recursos tradicionales de capital humano, es decir, en capacitación, experiencia y mérito, en lugar de estrategias alternativas asociadas a la conformación de redes, capital cultural y social.

Como consecuencia, las abogadas terminan haciendo un doble esfuerzo que las deja aún con menos tiempo, energías y posibilidades de significar las situaciones que perciben como obstáculo para su avance profesional.

\section{A propósito del derecho como una profesión} con una cultura masculina: las participantes reconocieron la existencia de una cultura masculina del derecho al identificar características diferentes asociadas a lo femenino y masculino, siendo las primeras percibidas de manera negativa, mientras que las segundas se inscriben a la imagen del abogado(a) ideal. No obstante, no articulan estas distinciones con la exigencia de un capital cultural determinado para ascender, sino que lo interpretan como características que deben adoptar para desenvolverse correctamente en la profesión legal.

Las participantes continúan invirtiendo fuertemente en recursos tradicionales de capital humano, pero no politizan la experiencia individual, ni perciben como estructurales sesgos relacionados con la existencia de un capital cultural determinado que devalúa lo femenino y fija el capital cultural de los hombres como opuesto al capital cultural de las mujeres.

3. Sobre la importancia del género como variable social: las abogadas entrevistadas identifican que, de una u otra forma, la variable género tiene algo que decir sobre su experiencia en la profesión. Así mismo reconocen que crear espacios de mujeres abogadas podría aportar a la realización de por lo menos tres objetivos: 1. Compartir vivencias comunes, que les permitan dar significado y reflexionar sobre las dificultades para las mujeres en el ejercicio profesional; 2. Crear redes de apoyo y empoderar a las mujeres; 3. Acceder a recursos de capital humano que no se pueden obtener de otra forma por falta de tiempo u otras dificultades.

Sin embargo, a la vez se muestran escépticas frente a la posibilidad de que las mujeres se unan en un proyecto común. La desconfianza y escepticismo frente a la solidaridad de género tiene como consecuencia que las mujeres continúen respondiendo desde lugares individuales, lo que dificulta un proyecto de mujeres abogadas. 
Aun con la carga del escepticismo, los sesgos de falta de compromiso y capacidad que rodean la maternidad son una preocupación generalizada entre las participantes, y por tanto un lugar a partir del que podría pensarse un proyecto común.

Las conclusiones de este trabajo permiten entonces replantear la hipótesis inicial en los siguientes términos: las mujeres registran dinámicas de discriminación en el ejercicio profesional, sin embargo las significan y justifican en sus experiencias individuales. Como consecuencia, antes que pensar en la reforma de la profesión legal o en un proyecto común de mujeres abogadas, invierten en recursos tradicionales de capital humano para sobrellevar situaciones de desventaja.

Si bien perciben la existencia de factores externos tanto de contenido estructural como cultural, no logran articular sus efectos sobre el propio proyecto profesional, más allá de la necesidad de adaptar la imagen que proyectan a estándares excesivos y contradictorios.

La posibilidad de construir un proyecto de las mujeres juristas debe partir de la generación de confianza y redes de trabajo y apoyo femeninas, a partir de las que las mujeres puedan optimizar sus oportunidades a nivel profesional.

\section{Referencias}

1. Ámbito Jurídico. (s. f.). ¿Demasiados abogados? Obtenido de ambitojuridico. com: http://www.ambitojuridico.com/ BancoConocimiento/N/noti-110614-07_ (demasiados_abogados)/noti-110614-07_ (demasiados_abogados).asp?print=1

2. Arango Gaviria, L. G. (2004). Jóvenes en la universidad: género, clase e identidad profesional. Bogotá: Siglo del Hombre Editores/ Universidad Nacional de Colombia.

3. Arango Gaviria, L. G. (2011). El trabajo de cuidado: ¿servidumbre, profesión o ingeniería emocional? En L. Arango y P. Molinier (Comp.), El trabajo y la ética del cuidado. Medellín: La Carreta Editores.

4. Badel, A. y Peña X. (Diciembre de 2010). Descomponiendo la brecha salarial de género con ajuste de sesgo de selección: el caso colombiano. Revista de Análisis Económico, 25(2), 169-191. Recuperado el 10 de octubre de 2012 de raeear: http://www. raeear.org/index.php/rae/article/view/ art25-6/497

5. Bergallo, P. (2006) ¿Un techo de cristal en el poder judicial? La selección de los jueces federales y nacionales en Buenos Aires. En L. Cabal y C. Mota, Más allá del Derecho. Justicia y género en América Latina. Bogotá: Siglo del Hombre Editores/Centre for Reproductive Rights/Ediciones Uniandes.

6. Boigeol, A. (2003). Male Strategies in the face of the femnisatios of a Profession. The Case of the French Judiciary. In U. Schultz \& G. Shaw, Women in the World's Legal Professions (págs. 295-321). Oxford-Portland Oregon: Hart Publishing. 
7. Crang, M., y Cook, I. (2007). Doing Ethnographies. London: Sage Publications.

8. Dumez Arias, J. M. (2010). Perfil del juez en la jurisdicción ordinaria. En G. V. Mauricio, Los abogados en Colombia. Bogotá: Editorial Universidad Nacional de Colombia.

9. Fedler, J. (1994). Women vs. Lawyer. Agenda, (21), 71-75. Recuperado el 18 de abril de 2011 de jstor: http://www.jstor.org/stable/4065825

10. Gabel, J. (1967). Formas de alienación. Ensayos sobre la falsa conciencia. Córdoba, Argentina: Editorial Universitaria de Córdoba.

11. Gorman, E. (Agosto de 2005). Gender Sterotypes, same gender preferences, and organizational variation in the hiring of women: Evidence from Law Firms. American Sociological Review, 7(4), 720-728. Recuperado el 18 de abril de 2011 de jstor: http://www. jstor.org/stable/4145383

12. Kay, F. M., y Hagan, J. (Junio de 1995). The persistent glass ceiling: gendered inequalities in earnings of lawyers. British Journal of Sociology, 46(2), 279-310. Recuperado el 16 de mayo de 2011 de jstor: http://www. jstor.org/stable/591789

13. kay, F., y Hagan J. (1998). Raising The Bar: The Gender Startificatios of Law Firm Capital. American Sociological Review, 63(5). Recuperado el 11 de mayo de 2011 de jstor: http://www.jstor.org/stable/2657336
14. Kohen, B. (2008). El género en la Justicia de Familia. Miradas y protagonistas. Buenos Aires: Editorial Ad Hoc.

15. Menkel-Meadow, C. (2013). Portia in a Different Voice: Speculations on a Women's Lawyering Process. Berkeley Women's L.J., 1(1), 39.63. Obtenido de: http://scholarship.law.berkeley.edu/bglj/vol1/iss1/2

16. New York City Bar. Committee on Women in the Profession. (February 7, 2006). Best Practices for the Hiring, Training, Retention, and Advancement of Women Attorneys (págs. 1-45). Obtenido de nycbar: http:// www2.nycbar.org/pdf/report/BestPractices4WomenAttorneys.pdf

17. Peña X., Hoyos, A. y Ñopo, H. (Mayo de 2010). La persistente brecha salarial de género en Colombia 1994-2006. En IBD Working Paper Series (págs. 1-31). Recuperado en octubre de 2011 de IDB: http://www.iadb.org/res/ publications/pubfiles/pubIDB-WP-174.pdf

18. Peña, X., Cárdenas, J. C., Ñopo, H. y Castañeda, J. L. (2014). Mujer, equidad y movilidad social. En A. Montenegro y M. Meléndez (Comp.), Equidad y movilidad social. Diagnósticos y propuestas para la transformación de la sociedad colombiana (págs 1-42). Bogotá: Universidad de los Andes, Facultad de Economía y Departamento Nacional de Planeación. 
19. Rhode, D. L. (2003). Gender and the profession: An American Perspective. En U. Schultz y G. Shaw, Women in the World's Legal Professions (págs. 1-31). Oxford-Portland Oregon: Hart Publishing.

20.Schultz, U. (2003a). Introduction: Women in the World's Legal Professions: Overview and Synthesis. En U. Schultz y G. Shaw, Women in the World's Legal Professions (págs. XXVI-IXII). Oxford-Portland Oregon: Hart Publishing.

21. Schultz, U. (2003b). Women Lawyers in Germany. Perception and construction of femininity. En U. Schultz y G. Shaw, Women in the
World's Legal Professions (págs. 295-321). Oxford-Portland Oregon: Hart Publishing.

22. Victoria Russi, Á. M. (2010). Caracterización del abogado en la administración pública nacional. En M. García Villegas, Los abogados en la administración pública nacional de Colombia (págs. 203-224). Bogotá: Editorial Universidad Nacional de Colombia.

23. Wills Obregón, M. E. (2007). Inclusión sin representación: la irrupción política de las mujeres en Colombia. 1970-2000. Bogotá: Grupo Editorial Norma. 